\title{
Identification of drug combinations administered by continuous subcutaneous infusion that require analysis for compatibility and stability
}

Andrew Dickman ${ }^{1 *}$ (D), Matthew Bickerstaff? ${ }^{2}$, Richard Jackson², Jennifer Schneider ${ }^{3}$, Stephen Mason ${ }^{1}$ and John Ellershaw'

\begin{abstract}
Background: A continuous subcutaneous infusion (CSCl) delivered via syringe pump is a method of drug administration used to maintain symptom control when a patient is no longer able to tolerate oral medication. Several classes of drugs, such as opioids, antiemetics, anticholinergics, antipsychotics and benzodiazepines are routinely administered by CSCl alone or in combinations. Previous studies attempting to identify the most-common CSCl combinations are now several years old and no longer reflect current clinical practice. The aim of this work was to review current clinical practice and identify CSCl drug combinations requiring analysis for chemical compatibility and stability.
\end{abstract}

Methods: UK pharmacy professionals involved in the delivery of care to palliative patients in hospitals and hospices were invited to enter $\mathrm{CSCl}$ combinations comprised of two or more drugs onto an electronic database over a 12-month period. In addition, a separate Delphi study with a panel of 15 expert healthcare professionals was completed to identify a maximum of five combinations of drugs used to treat more complex, but less commonly encountered symptoms unlikely to be identified by the national survey.

Results: A total of 57 individuals representing 33 separate palliative care services entered 1,945 drug combinations suitable for analysis, with 278 discrete combinations identified. The top 40 drug combinations represented nearly two-thirds of combinations recorded. A total of 23 different drugs were administered in combination and the median number of drugs in a combination was three. The Delphi study identified five combinations for the relief of complex or refractory symptoms.

Conclusion: This study represents the first step towards developing authoritative national guidance on the administration of drugs by CSCl. Further work will ensure healthcare practitioners have the knowledge and confidence that a prescribed combination will be both safe and efficacious.

Keywords: Palliative medicine, Drug combinations, Infusions, Subcutaneous, Delphi technique, Surveys, Questionnaires, Patient safety

\footnotetext{
* Correspondence: a.dickman@liverpool.ac.uk

${ }^{1}$ Marie Curie Palliative Care Institute Liverpool, Cancer Research Centre,

Liverpool L3 9TA, UK

Full list of author information is available at the end of the article
} 


\section{Background}

A continuous subcutaneous infusion (CSCI) is a method of drug administration used to maintain symptom control when a patient is no longer able to tolerate oral medication. A syringe pump (also referred to as a syringe driver) is used to deliver a CSCI, which is considered fundamental for continued symptom management in palliative care [1]. Several classes of drugs, such as opioids, antiemetics, anticholinergics, antipsychotics and benzodiazepines are routinely administered by CSCI alone or in combinations [2].

There have been several national surveys that have attempted to identify commonly used mixtures [3-6]. These studies, however, are several years old and do not reflect current practice. The most recent survey of CSCI use in the UK was performed over a decade ago in 2004 [6]. The majority of combinations contained either two or three drugs (44 and 30\% respectively) and an opioid was invariably a component. The authors concluded that compatibility and stability data were unavailable for more than half of the frequently used combinations. This is unsurprising for two reasons. Firstly, laboratory analysis is expensive and laborious. Secondly, the number of potential combinations is vast; Dickman et al. [2] identified 35 drugs that could be administered by CSCI, 11 of which were opioids. Based on these figures, there are theoretically 142,450 combinations (Fig. 1). Of course, certain combinations of drugs are impractical, so the number of clinically useful combinations is significantly lower. For example, for five non-opioids and one opioid, there are potentially 56 combinations comprising up to five drugs.

Parenteral administration of drugs is a recognised cause of medication error, and compatibility and stability of drug combinations is an issue of patient safety [7].
Despite widespread application in palliative care, there remain only three major sources of compatibility and stability information relating to CSCIs [2, 8, 9]. These reference sources provide information mainly about the visual compatibility of drug combinations, often relying on a clinical assessment to determine whether or not a particular combination is suitable for administration by CSCI. While many mixtures may appear physically compatible (i.e. clear, colourless and free from precipitation) the risk of chemical incompatibility cannot be ignored. There is a clear need to identify compatibility and stability of drug combinations administered by CSCI, especially those combinations most commonly prescribed. The aim of this project was to review current clinical practice to identify drug combinations that require analysis for chemical compatibility and stability.

\section{Methods}

In order to identify a list of drug combinations that would be subject to subsequent chemical analysis, two methods were employed: a national survey of practice and a Delphi study. This work was registered with the Liverpool Clinical Trials Unit (LCTU), which provided structured data monitoring, assessment and logistical support. Members of the Association of Supportive and Palliative Care Pharmacy (formerly Palliative Care Pharmacists' Network) were approached for both methods.

\section{National survey}

The national survey invited UK pharmacists and pharmacy technicians involved in the delivery of care to palliative patients in hospital and hospices to take part. Over a 12-month period, participants were asked to contribute to an anonymous web-based database that recorded information pertaining to CSCIs comprising

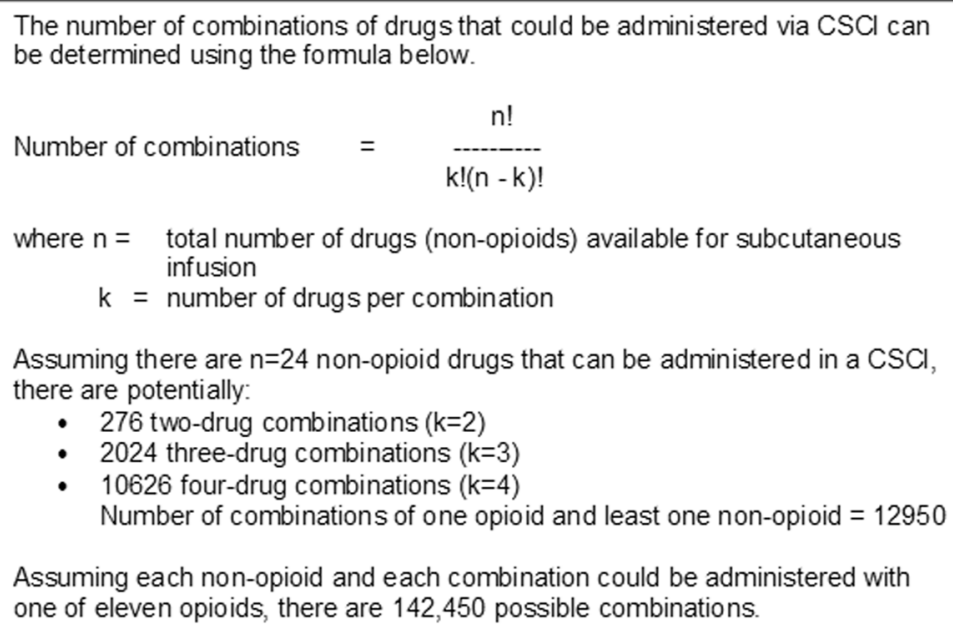

Fig. 1 Calculation of number of possible drug combinations. Adapted from reference [35] 
two or more drugs used for symptom management of patients aged 18 years and above during the last months or days of life. Participants entered information into the database about drug(s), dose(s), diluent used, total volume of infusion, duration of infusion and visual compatibility. The web-based system, designed and administered by LCTU, ensured patient anonymity while preventing duplication of entry. The database was analysed and a list describing the most frequent 40 combinations was produced. A literature search was then performed to determine if any the top 40 combinations identified by this national survey had already undergone chemical analysis.

\section{Delphi study}

In addition to the national survey, a Delphi study was undertaken using an online web questionnaire, hosted by www.smartsurvey.co.uk. The purpose of the Delphi study was to identify a maximum of five combinations of drugs used to treat more complex symptoms that required investigation for compatibility to improve the quality of patient care. This approach was deemed necessary as combinations prescribed for more difficult, but less commonly encountered symptoms, would not be identified by the national survey. The panel of experts in this study comprised 15 healthcare professionals split evenly between doctors, nurses and pharmacists. Each expert was required to have at least 5 years' palliative care clinical experience and be involved in the prescribing of, setting up of, or checking of CSCIs.

Pharmacists were contacted and asked if there was an interest to participate in this study, provided they met the criteria above. They were also requested to nominate senior medical and nursing staff at their place of work who met the criteria and were willing to participate. Experts were selected based on promptness of response to agree to participate. One week before disseminating each questionnaire, all the experts received a prenotification personalised email sent by the researcher. All further communication between researcher and respondents was indirect as the host website served as a conduit, ensuring respondent anonymity. All participants gave informed consent before attempting each questionnaire. The website hosting the survey anonymised the questionnaires, preventing identification of respondents by the researcher.

In the first-round of the Delphi study, the experts were asked to identify up to 10 combinations of drugs that had been used, or would have been used if there were compatibility data, for the management of complex or refractory symptoms. The experts were allowed complete freedom with their responses. A second literature search was undertaken to determine if any of the most common 25 combinations identified in the first- round of the Delphi study had already undergone chemical analysis. In the second round, the experts were required to select and rank ten combinations from the list of the 25 most common combinations of drugs identified in the first-round. In the final round, the experts were presented with the top 15 combinations derived from the second round and asked to rank them. Due to the potential for variability of responses, consensus agreement was based on the mean rank order. The top five drug combinations after three rounds were selected.

\section{Results}

A total of 57 individuals representing 33 separate palliative care services completed the national survey. At the time the database was locked, 1,945 combinations had been recorded (2,132 samples were collected, but 186 were excluded due to erroneous entry), with 278 discrete combinations of drugs being identified. Analysis of the database revealed 23 different drugs had been administered in combination by CSCI, six of which were opioids (see Table 1). The four most frequently prescribed drugs (midazolam, morphine, oxycodone and levomepromazine) accounted for $52 \%$ of all administered drugs. The median number of drugs administered by CSCI was three, with $50.6 \%$ of combinations comprising three or more drugs. Almost all CSCIs were administered over a duration of $24 \mathrm{~h}(1915 / 1945$; 98.5\%) with Water for Injections (WFI) being the most commonly used diluent $(1346 / 1945 ; 69.2 \%)$. An opioid was present in $91.5 \%$ of the combinations.

The top 40 represented nearly two-thirds of the 1,945 combinations recorded (see Table 2), comprising 20 twodrug, 19 three-drug and 1 four-drug combinations. Compatibility and stability data at clinically relevant doses were available for less than one third of the top 40 combinations [10-21].

The e-Delphi study was successfully completed by all 15 healthcare professionals, enabling the identification of five combinations used for complex or refractory symptoms that required analysis for compatibility and stability (see Table 3). No compatibility and stability data were found for these combinations. Only one of the five combinations appeared in the survey database (oxycodone, glycopyrronium and levomepromazine) and all comprised three drugs.

\section{Discussion}

This survey represents the most recent analysis of drug combinations administered by CSCI in the UK. The most commonly prescribed drug administered by CSCI was midazolam, while the most commonly prescribed opioid was morphine. Diamorphine was identified as the least commonly prescribed opioid. The previous national survey, however, identified diamorphine as the opioid 
Table 1 Frequency and doses of drugs that appeared in the database

\begin{tabular}{|c|c|c|c|c|c|}
\hline Drug & Frequency & $1^{\text {st }}$ quartile dose $(\mathrm{mg})$ & $3^{\text {rd }}$ quartile dose $(\mathrm{mg})$ & Mean dose (mg) & Median dose (mg) \\
\hline Midazolam & 1002 & 10 & 20 & 16.6 & 10.0 \\
\hline Morphine & 568 & 10 & 40 & 32.0 & 20.0 \\
\hline Oxycodone & 549 & 15 & 60 & 52.5 & 30.0 \\
\hline Levomepromazine & 514 & 6.25 & 25 & 22.0 & 12.5 \\
\hline Haloperidol & 492 & 2.5 & 3 & 3.0 & 3.0 \\
\hline Alfentanil & 359 & 2 & 14 & 37.8 & 5.0 \\
\hline Hyoscine butylbromide & 330 & 60 & 120 & 86.9 & 80.0 \\
\hline Diamorphine & 289 & 10 & 80 & 77.7 & 30.0 \\
\hline Metoclopramide & 276 & 30 & 60 & 49.8 & 40.0 \\
\hline Cyclizine & 171 & 150 & 150 & 143.4 & 150.0 \\
\hline Clonazepam & 165 & 0.5 & 2 & 1.72 & 1.0 \\
\hline Glycopyrronium & 116 & 0.6 & 1.2 & 1.13 & 1.2 \\
\hline Dexamethasone & 93 & 0.5 & 16 & 1.73 & 8.0 \\
\hline Octreotide & 56 & 0.3 & 1 & 0.5 & 0.6 \\
\hline Ketamine & 30 & 60 & 350 & 220.2 & 175.0 \\
\hline Ondansetron & 21 & 8 & 20 & 14.5 & 12.0 \\
\hline Granisetron & 12 & 2 & 4 & 3.25 & 3.5 \\
\hline Methadone & 12 & 35 & 60 & 44.8 & 52.5 \\
\hline Hyoscine hydrobromide & 8 & 0.6 & 1.6 & 1.3 & 1.4 \\
\hline Ketorolac & 5 & 60 & 60 & 60.0 & 60.0 \\
\hline Hydromorphone & 4 & 70 & 90 & 80.0 & 80.0 \\
\hline Ranitidine & 4 & 150 & 225 & 162.8 & 150.0 \\
\hline Diclofenac & 1 & 75 & 75 & 75.0 & 75.0 \\
\hline
\end{tabular}

most commonly administered by CSCI [6]. The worldwide shortage of diamorphine during the winter of 2004 forced services to adopt morphine as the opioid of choice and it would appear that many have not reverted to diamorphine. In 2012, the National Institute for Health and Clinical Excellence recommended that the parenteral opioid with the lowest acquisition cost (i.e. morphine) should be used first-line [22]. Diamorphine, with its superior solubility, appears to be generally reserved for patients with a relatively high opioid requirement, as reflected by mean and median doses of $77 \mathrm{mg}$ and $30 \mathrm{mg}$ respectively (Table 1 ).

A previous literature review found that only 70 drug combinations suitable for administration by CSCI had been investigated for compatibility and stability. The majority of these $(88.6 \%)$ referred to two-drug combinations [23]. Indeed, a review of the literature for the top 40 combinations identified by the national survey revealed that only $13(32.5 \%)$ have been analysed at clinically relevant doses for compatibility and stability, the majority of which comprised two drugs. The five combinations identified by the Delphi study were those mainly associated with the management of difficult or recalcitrant symptoms. Such combinations were expected to occur infrequently, a supposition vindicated by the appearance of only one combination in the database derived from the survey. These combinations often reflect specialist practice. It was unclear from the survey which area of practice the data were collected. A survey of specialist palliative care inpatient services only would be expected to identify a different list of commonly used combinations. Indeed, analysis of practice at a specialist palliative care inpatient unit revealed that $70 \%$ of the combinations comprised three or more drugs (compared to $50.6 \%$ in this survey) [24]. Since the majority of currently available compatibility and stability data refer to two-drug combinations, there is a disparity between available evidence and clinical practice.

A limitation of the Delphi technique is the risk of selection bias often associated with the choice of expert panel. Indeed, there are no universally accepted criteria for the selection of experts using the Delphi technique [25]. Selecting panel members through methods other than acquaintance is believed to minimise bias [26, 27]. In an attempt to reduce the risk of researcher bias, experts were selected for the Delphi study through a mix of promptness of response to the call to participate and snowballing. Both methods, however, may be associated 
Table 2 Top 40 combinations present in the 1,945 recorded CSCls

\begin{tabular}{|c|c|c|c|c|}
\hline \multicolumn{4}{|c|}{ Drug Combination } & \multirow[t]{2}{*}{ Frequency } \\
\hline Drug 1 & Drug 2 & Drug 3 & Drug 4 & \\
\hline Morphine & Midazolam & - & - & $124^{a}$ \\
\hline Oxycodone & Midazolam & - & - & $81^{a}$ \\
\hline Oxycodone & Levomepromazine & Midazolam & - & 60 \\
\hline Morphine & Metoclopramide & - & - & 57 \\
\hline Diamorphine & Midazolam & - & - & $55^{\mathrm{a}}$ \\
\hline Morphine & Levomepromazine & Midazolam & - & 53 \\
\hline Oxycodone & Haloperidol & Midazolam & - & 52 \\
\hline Oxycodone & Haloperidol & - & - & $49^{a}$ \\
\hline Morphine & Haloperidol & Midazolam & - & 46 \\
\hline Alfentanil & Haloperidol & - & - & 36 \\
\hline Oxycodone & Levomepromazine & - & - & $35^{\mathrm{a}}$ \\
\hline Alfentanil & Midazolam & - & - & 35 \\
\hline Alfentanil & Levomepromazine & Midazolam & - & 34 \\
\hline Morphine & Haloperidol & - & - & 29 \\
\hline Oxycodone & Metoclopramide & - & - & $29^{a}$ \\
\hline Oxycodone & Haloperidol & Hyoscine butylbromide & - & $29^{a}$ \\
\hline Morphine & Cyclizine & - & - & 28 \\
\hline Morphine & Levomepromazine & - & - & $22^{a}$ \\
\hline Alfentanil & Haloperidol & Midazolam & - & $22^{\mathrm{a}}$ \\
\hline Diamorphine & Metoclopramide & - & - & $21^{a}$ \\
\hline Alfentanil & Metoclopramide & - & - & 21 \\
\hline Alfentanil & Hyoscine butylbromide & Levomepromazine & - & 20 \\
\hline Oxycodone & Metoclopramide & Midazolam & - & 20 \\
\hline Diamorphine & Cyclizine & - & - & $19^{a}$ \\
\hline Diamorphine & Haloperidol & Midazolam & - & 19 \\
\hline Oxycodone & Hyoscine butylbromide & Midazolam & - & 18 \\
\hline Alfentanil & Hyoscine butylbromide & Levomepromazine & Midazolam & 18 \\
\hline Alfentanil & Metoclopramide & Midazolam & - & 17 \\
\hline Morphine & Hyoscine butylbromide & Midazolam & - & 17 \\
\hline Diamorphine & Levomepromazine & - & - & $17^{\mathrm{a}}$ \\
\hline Diamorphine & Levomepromazine & Midazolam & - & 17 \\
\hline Morphine & Haloperidol & Hyoscine butylbromide & - & 17 \\
\hline Morphine & Metoclopramide & Midazolam & - & 16 \\
\hline Morphine & Glycopyrronium & Midazolam & - & 15 \\
\hline Alfentanil & Cyclizine & - & - & 14 \\
\hline Oxycodone & Haloperidol & Hyoscine butylbromide & - & 14 \\
\hline Diamorphine & Haloperidol & - & - & $14^{a}$ \\
\hline Morphine & Hyoscine butylbromide & - & - & 13 \\
\hline Dexamethasone & Ketamine & - & - & 13 \\
\hline Diamorphine & Cyclizine & Midazolam & - & 13 \\
\hline
\end{tabular}

${ }^{a}$ combinations identified as being analysed at clinically relevant doses for compatibility and stability [10-21]; note that all analysed combinations were reported as compatible under stated conditions 
Table 3 Top 5 combinations identified by consensus from the e-Delphi study

\begin{tabular}{lllc}
\hline Combination & & \multicolumn{2}{c}{$\begin{array}{l}\text { Mean rank } \\
\text { score }\end{array}$} \\
\hline Drug 1 & Drug 2 & Drug 3 & 4.46 \\
\cline { 1 - 2 } Alfentanil & Hyoscine butylbromide & Octreotide & 6.00 \\
Oxycodone & Hyoscine butylbromide & Octreotide & 6.53 \\
Oxycodone & Glycopyrronium & Midazolam & 8.33 \\
Morphine & Dexamethasone & Ranitidine & 9.13 \\
Oxycodone & Ketamine & Levomepromazine & \\
\hline
\end{tabular}

with a potential for bias. A promptness to respond to the invitation and a willingness to participate suggests the expert has an interest in the subject under scrutiny, which carries a risk of self-selection bias. It has been proposed that there is an inherent bias in Delphi studies because experts may volunteer to take part as they hold particular views about the subject matter, which could influence the consensus process [28]. Nonetheless, it has been shown that those who are willing to participate in expert panels are representative of their unwilling colleagues [29]. The 'snowballing' technique is a conventional recruitment method in Delphi research [30-32]. This technique, however, could have led to selection bias because of its unrepresentative approach by potentially limiting the breadth of experience and geographical distribution of participants [33, 34].

\section{Conclusion}

Further work based on the outcomes of this study will ensure that healthcare practitioners will have the knowledge and confidence that a prescribed combination can be safely administered and that the expected therapeutic goal will be achieved. Given the dispersion of doses within the dataset for each drug, analysis utilising the first and third quartiles are recommended for any future compatibility tests. This study represents the first step towards developing an authoritative national guide which will inform healthcare professionals about the administration of drugs by a CSCI.

\section{Abbreviations}

CSCl: Continuous subcutaneous infusion; UK: United Kingdom; WFI: Water for injections

\section{Acknowledgements}

Not applicable.

\section{Funding}

Supported by a research grant from Marie Curie Cancer Care (C38813/A12566), which had no role in the design of the study, data collection and analysis, or writing of the manuscript.

\section{Availability of data and materials}

The datasets used and analysed during the current study are available from the corresponding author on reasonable request.

\section{Authors' contributions}

$A D, J S, S M$ and JE conceived and designed the study. MB designed and managed the data collection. AD, JS and RJ were involved in the analysis and interpretation of data. AD drafted the manuscript. All authors read and approved the final manuscript and have assumed accountability for all aspects of the work.

\section{Competing interests}

The authors declare that they have no competing interests.

\section{Consent for publication}

Not applicable.

\section{Ethics approval and consent to participate}

Ethics approval was granted by NRES Committee North West - Cheshire, Barlow House, 3rd Floor, 4 Minshull Street, Manchester M1 3DZ. Reference $12 /$ NW/0436. For the national survey, consent was implied through agreement to participate. For the Delphi, participants gave informed consent before completing each questionnaire.

\section{Publisher's Note}

Springer Nature remains neutral with regard to jurisdictional claims in published maps and institutional affiliations.

\section{Author details}

${ }^{1}$ Marie Curie Palliative Care Institute Liverpool, Cancer Research Centre, Liverpool L3 9TA, UK. ${ }^{2}$ Cancer Research UK Liverpool Cancer Trials Unit, University of Liverpool, Liverpool L69 3GL, UK. ${ }^{3}$ School of Biomedical Sciences and Pharmacy, Faculty of Health and Medicine, University of Newcastle, Newcastle, Australia.

Received: 14 October 2016 Accepted: 16 March 2017

Published online: 23 March 2017

\section{References}

1. Graham F, Clark D. The syringe driver and the subcutaneous route in palliative care: the inventor, the history and the implications. J Pain Symptom Manage. 2005;29(1):32-40.

2. Dickman A, Schneider J. The Syringe Driver: Continuous Subcutaneous Infusions in Palliative Care. 3rd ed. Oxford: Oxford University Press; 2011.

3. David J. A survey of the use of syringe drivers in Marie Curie Centres. Eur J Cancer Care. 1992;1(4):23-8.

4. Johnson I, Patterson S. Drugs used in combination in the syringe driver-a survey of hospice practice. Palliat Med. 1992;6(2):125-30.

5. O'Doherty CA, Hall EJ, Schofield L, Zeppetella G. Drugs and syringe drivers: a survey of adult specialist palliative care practice in the United Kingdom and Eire. Palliat Med. 2001:15(2):149-54.

6. Wilcock A, Jacob JK, Charlesworth S, Harris E, et al. Drugs given by a syringe driver: a prospective multicentre survey of palliative care services in the UK. Palliat Med. 2006;20(7):661-4.

7. Nemec K, Kopelent-Frank H, Greif R. Standardization of infusion solutions to reduce the risk of incompatibility. Am J Health Syst Pharm. 2008;65(17): 1648-54.

8. Palliativedrugs.com. Syringe Driver Survey Database. 2015. Available at: www.palliativedrugs.com. [Accessed 14 June 2015].

9. Palliative Care Matters. Sdrivers - Drug Compatibility database. 2015. Available at www.pallcare.info. [Accessed 14 June 2015].

10. National Institute for Health and Clinical Excellence (NICE) 2012. Opioids in palliative care: safe and effective prescribing of strong opioids for pain in palliative care of adults. GG140. Available from: http://guidance.nice.org.uk/ cg140. (Accessed 4 Mar 2016).

11. LeBelle MJ, Savard C, Gagnon A. Compatibility of morphine and midazolam or haloperidol in parenteral admixtures. Can J Hosp Pharm. 1995;48(3):155-60.

12. Gardiner PR. Compatibility of an injectable oxycodone formulation with typical diluents, syringes, tubings, infusion bags and drugs for potential co-administration. Hosp Pharm. 2003;10:354-61.

13. Hines $\mathrm{S}$, Pleasance $\mathrm{S}$. Compatibility of an injectable high strength oxycodone formulation with typical diluents, syringes, tubings, infusion bags and drugs for potential co-administration. EJHP Pract. 2009;15(5):32-8. 
14. Allwood MC, Brown PW, Lee M. Stability of injections containing diamorphine and midazolam in plastic syringes. Int J Pharm Pract. 1994;3(1):57-9.

15. Dickman A, Roberts E, Bickerstaff M, Jackson R, et al. Chemical compatibility/ stability of commonly used drug combinations administered by continuous subcutaneous infusions for end of life care. Support Care Cancer. 2015;23 Suppl 1:S202.

16. Al-Tannak NF, Cable CG, McArthur DA, Watson DG. A stability indicating assay for a combination of morphine sulphate with levomepromazine hydrochloride used in palliative care. J Clin Pharm Ther. 2012;37(1):71-3.

17. Storey P, Hill HH, St. Louis RH, Tarver EE. Subcutaneous infusions for control of cancer symptoms. J Pain Symptom Manage. 1990;5(1):33-41.

18. Dickman A, Kean H, Ellershaw J, Rigge D, Weir D. Chemical Compatibility/ Stability of Alfentanil with Commonly Used Supportive Drug Combinations Administered by Continuous Subcutaneous Infusions for End of Life Care. Poster presented at: 12th Congress of the European Association of Palliative Care; 18-21 May 2011; Lisbon.

19. Allwood MC. Diamorphine mixed with antiemetic drugs in plastic syringes. Br J Pharm Pract. 1984;6:88-90

20. Regnard C, Pashley S, Westrope F. Anti-emetic/diamorphine mixture compatibility in infusion pumps. Br J Pharm Pract. 1986;8:218-20.

21. Grassby PF, Hutchings L. Drug combinations in syringe drivers: the compatibility and stability of diamorphine with cyclizine and haloperidol. Palliat Med. 1997;11(3):217-24.

22. Dickman A, Kean H, Rigge D, Weir P, Ellershaw J. Chemical Compatibility/ Stability of Common Drug Combinations Administered by Continuous Subcutaneous Infusions for End of Life Care. Palliat Med. 2010;24(4 Suppl): S141.

23. Dickman A. Continuous subcutaneous infusions - are we certain the patient is getting what we prescribe? Poster presented at: 13th World Congress of the European Association for Palliative Care; May 30 June 2 2013; Prague.

24. Dickman A. Drugs and Continuous Subcutaneous Infusions - A Study to Identify Common Combinations. Poster presented at: 8th Palliative Care Congress; March 10-12 2010; Bournemouth.

25. Keeney S, Hasson F, McKenna H. Consulting the oracle: ten lessons from using the Delphi technique in nursing research. J Adv Nurs. 2006; 53(2):205-12.

26. Powell C. The Delphi technique: myths and realities. J Adv Nurs. 2003;41(4): 376-82.

27. Murphy MK, Black NA, Lamping DL, McKee CM, Sanderson CF, et al. Consensus development methods, and their use in clinical guideline development. Health Technol Assess. 1998;2(3):i-iv. 1-88.

28. Hill KQ, Fowles J. The methodological worth of the Delphi forecasting technique. Technol Forecast Soc. 1975;7(2):179-92.

29. McKee M, Priest P, Ginzler M, Black N. How representative are members of expert panels? Qual Assur Health Care. 1991;3(2):89-94.

30. Lakke SE, Wittink H, Geertzen JH, van der Schans CP, Reneman MF. Factors that affect functional capacity in patients with musculoskeletal pain: a Delphi study among scientists, clinicians, and patients. Arch Phys Med Rehabil. 2012;93(3):446-57.

31. Pesut B, McLeod B, Hole R, Dalhuisen M. Rural nursing and quality end-oflife care: palliative care ... palliative approach ... or somewhere inbetween? ANS Adv Nurs Sci. 2012;35(4):288-304.

32. Letrilliart L, Milliat-Guittard L, Romestaing P, Schott AM, et al. Building a shared patient record for breast cancer management: a French Delphi study. Eur J Cancer Care (Engl). 2009;18(2):131-9.

33. Steurer J. The Delphi method: an efficient procedure to generate knowledge. Skeletal Radiol. 2011;40(8):959-61.

34. Izal M, Nuevo R, Montorio I, Pérez-Rojo G. Method of recruitment and the scores of self-report measures: the example of worry in the elderly. Arch Gerontol Geriatr. 2009;48(1):45-9.

35. Boslaugh S, Watters PA. Statistics in a Nutshell. Sebastopol: O'Reilly Media Inc; 2008.

\section{Submit your next manuscript to BioMed Central and we will help you at every step:}

- We accept pre-submission inquiries

- Our selector tool helps you to find the most relevant journal

- We provide round the clock customer support

- Convenient online submission

- Thorough peer review

- Inclusion in PubMed and all major indexing services

- Maximum visibility for your research

Submit your manuscript at www.biomedcentral.com/submit

) Biomed Central 